\title{
Prevalence and risk factors of posttraumatic stress disorder among survivors five years after the "Wenchuan" earthquake in China
}

\author{
Li-Ping Zhang ${ }^{1,2 \dagger}$, Qian Zhao ${ }^{3 \dagger}$, Zhong-Cheng Luo ${ }^{4}$, Yi-Xiong Lei ${ }^{3}$, Yu Wang ${ }^{1}$ and Pei-Xi Wang ${ }^{2,3^{*}}$
}

\begin{abstract}
Objective: The aim of this study was to investigate the prevalence of posttraumatic stress disorder (PTSD) and its risk factors among survivors in a heavily-hit area five years after the Wenchuan earthquake in 2008, China.

Methods: 684 survivors from Beichuan county, the center of the Wenchuan Earthquake in 2008, were evaluated using the PTSD Checklist-Civilian Version (PCL-C) questionnaire in 2013.

Results: The prevalence of PTSD among survivors was $9.2 \%$ in 2013. Significant risk factors of PTSD included gender (females $12.1 \%$, males $5.2 \%$ ), age (18-35 y $0.8 \%, 36-59$ y $9.7 \%, \geq 60$ y $12.9 \%$ ), occupation (farmers $12.2 \%$, non-farmers 1.6\%), education (less than high school 11.0\%; > = high school 0.8\%) and family member loss (yes: 12.4\%, no: 7.3\%). Multivariate logistic regression showed that females, older people, farmers and those with family member loss were significantly more likely to develop PTSD.

Conclusions: Posttraumatic stress symptoms remained relatively common among survivors five years after the "5.12" Earthquake in Beichuan county, China. It is important to provide psychological aid and social support for survivors to decease health burden from PTSD, especially for females, farmers, old age survivors and those with family member loss.
\end{abstract}

Keywords: Posttraumatic stress disorder, Survivors, Risk factors, Wenchuan earthquake

\section{Background}

On May 12, 2008, a major earthquake measuring 8.0 on the Richter scale hit Wenchuan country, Sichuan province of Southwest China. The "5.12" Wenchuan earthquake was the most violent earthquake in China since Tangshan earthquake measuring 7.8 on the Richter scale in 1976. During the earthquake, 69,227 people were dead and 374,643 got injured. The total property damages cost over 150 billion dollars [1].

Many studies have detected a variety of psychological problems following the " 5.12 " Wenchuan earthquake, especially posttraumatic stress disorder (PTSD) [2-4]. PTSD usually occurs one month after a disaster and could cause a series of psychological and physiological

\footnotetext{
*Correspondence: peixi001@163.com

${ }^{\dagger}$ Equal contributors

${ }^{2}$ Institute of Public Health, School of Nursing , Henan University, Jinming Campus, Kaifeng, HN 475004, China

${ }^{3}$ School of Public Health, Guangzhou Medical University, Guangzhou, China Full list of author information is available at the end of the article
}

problems including intrusive re-experiencing, avoidance, numbness and hyper-arousal [5].

When a large scale disaster such as earthquake happens, usually PTSD would also develop [6-8]. About two thirds PTSD patients could recover over time, while others would become more serious, and the posttraumatic state could continue further to affect their cognitive and behavior functions for several years or even longer [9].

Previous studies have shown that PTSD is a common problem of mental health among survivors after natural disasters. According to a study about the Taiwan 9.21 earthquake, the PTSD rate was $20.9 \%$ among survivors who experienced the disaster 2 years after the earthquake [10]. The PTSD rate was $23 \%$ among orphans thirty years after the Tangshan earthquake in 1976, China [9]. For the Morocco earthquake, $10 \%$ of survivors developed posttraumatic stress symptoms forty years after the earthquake [11]. 
In this study, we assessed the prevalence and risk factors of PTSD among survivors five years after the Wenchuan earthquake. The prevalence of PTSD for survivors from the area of Beichuan was $12 \%$ about 2 years after the disaster in 2010 [12]. Continuing long-term monitoring of PTSD rates among survivors after the disaster could provide important information for implementing necessary community-based psychological aids in disaster areas. Five years after the disaster is an important time window in that subjects who remained to be suffered from PTSD after 5-y may need stronger psychological aid and treatment to recover. However, there is a lack of data on posttraumatic stress symptoms among survivors five years after the Wenchuan earthquake. This study thus aimed to investigate the prevalence and risk factors of PTSD among survivors five years after the Wenchuan earthquake.

\section{Methods}

\section{Participants}

All participants were recruited from Leigu Town with about 7,700 people. Most people in this community were originally native inhabitants of Leigu Town, a subordinate town of Beichuan County, which is the epicenter of the earthquake where $80 \%$ of the houses collapsed and more than 1,000 people died. Because Leigu Town was a severely afflicted area in the earthquake, almost all survivors received psychological aids after the earthquake. The survivors were the target population in this study, and were sampled from all household units in this community. A method of systematic sampling was adopted according to household unit doorplate number, and 730 families were selected. The sampling ratio was about $30 \%$. Only one participant within a family was recruited for interview to ensure independence of study subjects, which is usually the household host if available. The inclusion criteria are as: (1) willing to participate, over 18 years old, clear consciousness and without language disorders; (2) experienced the Wenchuan earthquake in Beichuan county on May 12, 2008. The exclusion criteria include: (1) mental retardation, dementia, or any other major psychosis (e.g., schizophrenia, major depressive disorders, and severe mental disorders); (2) Failure to be reached after three household visits or refuse to be interviewed. If a sampled individual was unavailable, the next available individual was sampled. We have inquired the participant about the mental health before the earthquake. If they had similar symptoms such as depression, anxiety or another psychological problem, they would be excluded.

Since 2010, Community Health Service Center in China has set up a health care information system with data on all residents with major psychosis in the network of basic community public health care centers. The community health care information system maintains a list of residents with mental retardation, dementia, or any other major psychosis diagnosed by community doctors using questionnaires such as Mini-Mental State Examination (MMSE) and the General Health Questionnaire (GHQ12). According to the list from the community health care information system, residents with mental retardation, dementia, or any other major psychosis were excluded.

\section{Procedures}

The study was approved by the research ethics committee of Panzhihua University in Feb, 2013(reference number: 2013026). Written informed consent was obtained from all study participants. More than 20 voluntary individuals who can speak local dialect received training by the study investigators on communication and interviewing skills before the data collection. They were divided into six groups and all interview groups have been provided a professional physician. At the same time, we paid a return visit by random sampling to monitor the volunteers [13]. Interviewers visited the study community for data collection over 1 month between July 15 and August 15, 2013.

There were about 2300 families and 7700 people in this community. Systematic sampling by house doorplate number in three was conducted, and 730 families were selected. For the majority of families, there are three or more family members. Only one eligible resident in each family was recruited, usually a household host if available. We have chosen to recruit the first host we met for each family. If all family members were absent for one month or refused to be interviewed, the family with the next doorplate number would be selected as a replacement. If families with 2 or 3 consecutive doorplate numbers, all did not respond, the next ten doorplate numbers would be considered for recruitment. A total of 26 families refused to be interviewed, 20 families were not reachable within 1 month and 11 people that were unavailable because of mental problem. The final study cohort included 684 participants from Beichuan County who were representative of survivors in the heavily hit area.

All participants were interviewed using a structured interview questionnaire to obtain data on sociodemographic characteristics (age, gender, marital status, education, occupation) and earthquake related losses (property damage, personal injury, family member death). Posttraumatic stress symptoms were assessed using the subscale of PTSD Checklist-Civilian Version (PCL-C), which is the internationally recognized screen tool for PTSD with high reliability and validity $[14,15]$. The instrument is a self-reported 17-item symptom scale that corresponds to DSM-IV criteria [15]. The diagnosis of PTSD was determined by a clinical psychologist using the 
Chinese version of PCL-C $[14,16,17]$ with Cronbach alpha coefficient of 0.82 and split-half reliability of 0.65 [16].

The 17 items of PCL-C each is with a score from 1 to 5: 1 = not at all; 2 = a little; 3 = quite a bit; 4 = extremely; $5=$ very extremely. The maximal total score for 17 items is 85 . Participant with a score of 50 or greater was classified as having probable PTSD. With PCL-C score of 50 as the diagnostic cut-off, the sensitivity was approximately $80 \%$ [18]. This cut-off point was used in the present study to identify PTSD cases.

According to the 4th edition of Diagnostic and Statistical Manual of Mental Disorder (DSM-IV) proposed by the Harvard Refugee Trauma Group [19], PTSD includes three groups of symptoms: B (intrusive re-experiencing, 5 items), $C$ (avoidance or numbness, 7 items) and D (hyper-arousal, 5 items). Symptoms B positive group requires at least one of the five intrusive re-experiencing items to get a score of over 3. Symptoms C positive group requires at least three of the seven avoidance and numbness items to get a score of over 3 . Symptoms D positive group requires at least two of the five hyperarousal items to get a score of over 3 [19]. Cronbach's alpha coefficient is 0.84 . In this study, we did not use DSSM-IV criteria but used PCL-C score of 50 as the diagnostic cut-off. We compared the frequency of different PTSD symptoms (B, C, D) among all subjects as well as probable PTSD sufferers.

\section{Statistical analysis}

All data were analyzed by statistical software SPSS 17.0 (SPSS, Chicago, Illinois, USA). Descriptive statistics were computed for demographic characteristic variables. Chisquare test was used to examine differences in categorical variables between those who were suffered from PTSD and those who were not. Multivariate logistic regression was used to assess the risk factors of PTSD.

\section{Results}

Table 1 shows the main characteristics of participants. Males comprised $42.1 \%$ of the study sample. The average age was 51.8 years. About $37.3 \%$ of participants were $>=60$ years of age and $71.9 \%$ were farmers. A total of $37.7 \%$ of participants had family member loss in the earthquake.

As recommended by DSM-IV, total score over 50 was considered probable PTSD. The percentages of probable cases according to participants' characteristics are shown in Table 2. A total of 63 participants (9.2\%) had DSM-IV total score of over 50, and were identified as "probable PTSD cases". The average PCL-C score was 31.98 (standard deviation $(\mathrm{SD})=12.07$ ). The significant variables identified for PTSD were gender, age group, education level, occupation and family member loss (all $\mathrm{p}<0.05)$.
Table 1 Participants' characteristics in the study cohort ( $N=684)$

\begin{tabular}{|c|c|c|c|}
\hline Variables & & $\mathbf{n}$ & $\%$ \\
\hline \multicolumn{4}{|l|}{ Gender } \\
\hline & Male & 288 & 42.1 \\
\hline & Female & 396 & 57.9 \\
\hline \multicolumn{4}{|c|}{ Marital status } \\
\hline & Single/divorced/widowed & 176 & 25.7 \\
\hline & Married & 508 & 74.3 \\
\hline \multicolumn{4}{|c|}{ Age (years) } \\
\hline & $18-35$ & 129 & 18.8 \\
\hline & $36-59$ & 300 & 43.9 \\
\hline & $\geq 60$ & 255 & 37.3 \\
\hline \multicolumn{4}{|c|}{ Education level } \\
\hline & Less than high school & 566 & 82.8 \\
\hline & High school & 66 & 9.6 \\
\hline & More than high school & 52 & 7.6 \\
\hline \multicolumn{4}{|c|}{ Occupation } \\
\hline & Farmer & 492 & 71.9 \\
\hline & employee & 95 & 13.9 \\
\hline & Self-employed & 55 & 8.1 \\
\hline & Student & 42 & 6.1 \\
\hline \multicolumn{4}{|l|}{ Ethnicity } \\
\hline & Han & 377 & 55.1 \\
\hline & Qiang (ethnic minority) & 307 & 44.9 \\
\hline \multicolumn{4}{|c|}{ Property loss } \\
\hline & Less(<10000 RMB/ 6135 USD) & 110 & 16.1 \\
\hline & $\operatorname{Large}(>=10000 \mathrm{RMB} / 6135$ USD) & 574 & 83.9 \\
\hline \multicolumn{4}{|l|}{ Loss } \\
\hline & Family member died & 258 & 37.7 \\
\hline & Family member injured & 82 & 12.0 \\
\hline & Injury to self & 25 & 3.7 \\
\hline & No death, no injury & 319 & 46.6 \\
\hline
\end{tabular}

Table 3 shows the frequencies of different PTSD symptoms. Among all 684 participants, the positive rates were $24.4 \%$ for "intrusive re-experiencing" group (B group), $4.4 \%$ for "avoidance and numbing" group ( $\mathrm{C}$ group), and $13.2 \%$ for "hyper-arousal" group (D group), respectively. In subgroups, for items "Recurrent and intrusive distressing recollections", "Intense psychological distress to cues" and "physiological reactivity to cues" PTSD symptoms appeared relatively frequently $(15.5 \%, 15.5 \%$ and $15.6 \%$ respectively), while for items "detachment or estrangement feelings" and "restricted range of affect" the symptoms occurred relatively infrequently ( $2.8 \%$ and $2.5 \%$ respectively). Among the 63 probable PTSD participants, the percentages of positive symptoms for "intrusive re-experiencing", "avoidance and numbing" and "hyper-arousal" groups 
Table 2 Proportion of PTSD by participants' characteristics

\begin{tabular}{|c|c|c|c|c|}
\hline Variables & N. of participants & Probable PTSD cases & Rate (\%) & $\mathrm{p}$ value \\
\hline Overall & 684 & 63 & 9.2 & \\
\hline Gender & & & & $0.002^{*}$ \\
\hline Male & 288 & 15 & 5.2 & \\
\hline Female & 396 & 48 & 12.1 & \\
\hline Marital status & & & & 0.588 \\
\hline Single/divorced/widowed & 176 & 18 & 10.2 & \\
\hline Married & 508 & 45 & 8.9 & \\
\hline Age (years) & & & & $<0.001^{*}$ \\
\hline $18-35$ & 129 & 1 & 0.8 & \\
\hline $36-59$ & 300 & 29 & 9.7 & \\
\hline$\geq 60$ & 255 & 33 & 12.9 & \\
\hline Education level & & & & $0.001^{*}$ \\
\hline Less than high school & 566 & 62 & 11.0 & \\
\hline$>=$ High school & 118 & 1 & 0.8 & \\
\hline Occupation & & & & $<0.001^{*}$ \\
\hline Farmer & 492 & 60 & 12.2 & \\
\hline Non-farmer & 192 & 3 & 1.6 & \\
\hline Ethnicity & & & & 0.209 \\
\hline Han & 377 & 30 & 8.0 & \\
\hline Qiang & 307 & 33 & 10.7 & \\
\hline Property loss & & & & 0.443 \\
\hline Less(<10000 RMB/ 6135 USD) & 110 & 8 & 7.3 & \\
\hline Large $(>=10000$ RMB/ 6135 USD) & 574 & 55 & 9.6 & \\
\hline Family member died & & & & $0.025^{*}$ \\
\hline No & 426 & 31 & 7.3 & \\
\hline Yes & 258 & 32 & 12.4 & \\
\hline Family member injured & & & & 0.822 \\
\hline No & 602 & 56 & 9.3 & \\
\hline Yes & 82 & 7 & 8.5 & \\
\hline Injury to self & & & & 0.232 \\
\hline No & 659 & 59 & 9.0 & \\
\hline Yes & 25 & 4 & 16.0 & \\
\hline
\end{tabular}

PTSD $=$ posttraumatic stress disorder.

${ }^{*} \mathrm{P}<=0.05$.

were $84.1 \%, 34.9 \%$ and $52.4 \%$ respectively. The positive rates for the 17 items concerning PTSD symptoms varied from $20.6 \%$ to $76.2 \%$. The highest items included "Intense psychological distress to cues" (73.0\%) and "physiological reactivity to cues" (76.2\%). The lowest item was "detachment or estrangement feelings" (20.6\%).

In Table 2, we have find five significant variables identified for PTSD were gender, age group, education level, occupation and family member loss $(\mathrm{p}<0.05)$. The second order interactions between those 5 variables were tested with the Logistic regression model and we did not find any significant interaction $(\mathrm{p}>0.05)$. The significant risk factors of PTSD in a multivariate logistic regression model are shown in Table 4. Female gender $(\mathrm{OR}=$ 2.08 ), older age (36-59 y: OR $=7.52, \geq 60$ y: $\mathrm{OR}=9.64$, vs. $<36 \mathrm{y})$, occupation of farmer $(\mathrm{OR}=4.37)$ and family member loss $(\mathrm{OR}=1.88)$ were associated with significantly elevated risks of PTSD.

\section{Discussion}

According to previous studies of the Wenchuan earthquake, the PTSD rate among survivors was $45.5 \%$ two and a half months after the earthquake [4]. The prevalence of probable PTSD among adults was $37.8 \%$ three 
Table 3 The frequency of different PTSD symptoms among all subjects (684) and probable PTSD sufferers $(n=63)$

\begin{tabular}{|c|c|c|}
\hline Variables & All n (\%) & PTSD n (\%) \\
\hline B group & $167(24.4)$ & $53(84.1)$ \\
\hline \multicolumn{3}{|l|}{ Intrusive re-experiencing (at least one required) } \\
\hline - Recurrent and intrusive distressing recollections & $106(15.5)$ & $36(57.1)$ \\
\hline - Recurrent distressing dreams & $57(8.3)$ & $25(39.7)$ \\
\hline - Acting or feeling as if events recurring & $81(11.8)$ & $40(63.5)$ \\
\hline - Intense psychological distress to cues & $106(15.5)$ & $46(73.0)$ \\
\hline - Physiological reactivity to cues & $107(15.6)$ & $48(76.2)$ \\
\hline C group & $30(4.4)$ & $22(34.9)$ \\
\hline \multicolumn{3}{|l|}{ Avoidance and numbing (at least three required) } \\
\hline - Avoidance of thoughts, feelings and conversations & $54(7.9)$ & $32(50.8)$ \\
\hline - Avoidance of reminders & $56(8.2)$ & $28(44.4)$ \\
\hline - Psychogenic amnesia & $26(3.8)$ & $17(27.0)$ \\
\hline -Markedly diminished interest in significant activities & $22(3.2)$ & $15(23.8)$ \\
\hline - Detachment or estrangement feelings & $19(2.8)$ & $13(20.6)$ \\
\hline - Restricted range of affect & $17(2.5)$ & $15(23.8)$ \\
\hline - Sense of a foreshortened future & $42(6.1)$ & $24(38.1)$ \\
\hline D group & $90(13.2)$ & $33(52.4)$ \\
\hline \multicolumn{3}{|l|}{ Hyper-arousal (at least two required) } \\
\hline - Sleep difficulty & $62(9.1)$ & $23(36.5)$ \\
\hline - Irritability or outbursts of anger & $37(5.4)$ & $18(28.6)$ \\
\hline - Difficulty concentrating & $34(5.0)$ & $19(30.2)$ \\
\hline • Hyper-vigilance & $84(12.3)$ & $29(46.0)$ \\
\hline - Exaggerated startle response & $81(11.8)$ & $30(47.6)$ \\
\hline
\end{tabular}

PTSD = posttraumatic stress disorder.

months after the earthquake in Leigu Town [3], and 13.4\% among children one year after the earthquake [20]. The probable PTSD rate in a heavily-hit area three years after the quake was $11.2 \%$ [21]. In the current study, we identified that the probable PTSD rate in a heavily-hit area five years after the earthquake was $9.2 \%$, only $2.0 \%$ lower than the rate three years after the earthquake. This prevalence of PTSD is much higher than that in the general Chinese population, which was $0.2 \%$ [22].

We noted that the prevalence of PTSD seemed to decrease over time, but at a relatively slow pace. The declining prevalence may be attributable to self-healing capabilities, social support and psychological aid. Social support and psychological aid are shown to be associated with the quality of life in earthquake survivors [23]. Since at five years after the earthquake, the prevalence rate remains as high as near $10 \%$, appropriate psychological aids may be warranted.

Significant risk factors for PTSD five years after the earthquake were female gender, old age ( $\geq 60$ year), farmer occupation and family member loss. These findings are plausible. Our finding that the prevalence of PTSD was significantly higher among females (12.1\%) compared with males $(5.2 \%)$ is consistent with previous findings [2-4,24]. It seems that women exposed to traumatic events are more likely to develop PTSD than men.

Farmers appeared to be more likely to be suffered from PTSD. The incomes of farmers are generally low. They perhaps had fewer resources in coping with the devastating stress from the loss of economic support and living means than people of other occupations. This may result in a higher PTSD rate in farmers.

Survivors with family member loss may undertake more negative trauma, and have more economic and psychological pressure, which may result in a higher prevalence rate of PTSD [25].

Among all 63 probable PTSD sufferers, the items "physiological reactivity to cues" (76.2\%) and "intense psychological distress to cues" (73.0\%) occurred most frequently, suggesting more mental interventions concerning these symptoms would be helpful. Additionally, the majority of common PTSD symptoms are different 


\section{Table 4 Significant risk factors of posttraumatic stress disorder from multivariate stepwise logistic regression models}

\begin{tabular}{llllll}
\hline Variable & $\boldsymbol{\beta}$ & SE & OR & $\mathbf{9 5 \%} \mathrm{Cl}$ & $\boldsymbol{P}$ \\
\hline $\begin{array}{l}\text { Gender } \\
\text { Male }\end{array}$ & & & & & \\
$\quad$ Female & 0.73 & 0.315 & 2.08 & $1.12-3.85$ & 0.02 \\
Age (years) & & & & & \\
$\quad$ 18-35 & & & 1.0 & & \\
$\quad 36-59$ & 2.02 & 1.040 & 7.52 & $1.03-57.75$ & 0.05 \\
$\geq 60$ & 2.27 & 1.043 & 9.64 & $1.25-74.46$ & 0.03 \\
Occupation & & & & & \\
$\quad$ Non-farmer & & & 1.0 & & \\
$\quad$ Farmer & 1.48 & 0.617 & 4.37 & $1.30-14.66$ & 0.02 \\
Family member died & & & & & \\
$\quad$ No & & & 1.0 & & \\
$\quad$ Yes & 0.63 & 0.273 & 1.88 & $1.10-3.21$ & 0.02 \\
Constant & -7.02 & 1.217 & 0.001 & & $<0.001$ \\
\hline
\end{tabular}

Variables considered for inclusion in the regression model were gender, marital status, age, education level, occupation, ethnicity, property loss, family member died, family member injured, Injury to self.

Only significant predictor variable were included in the final model. $\beta=$ partial Regression Coefficient; SE = Standard Error; OR = Odds Ratio; $\mathrm{Cl}=$ Confidence Interval.

for probable PTSD sufferers and others, suggesting different psychological aid may be needed. Communitybased mental health aid may be helpful [26].

This study has limitations to acknowledge. First, in the current study participants with a score of 50 or above were classified as having probable PTSD without a clinical interview. This diagnostic criterion is often used when a clinical interview is not feasible [27]. It is expected that this method may not have optimal sensitivity and specificity. Second, the study sample was from a single town in a heavily-hit earthquake area in China. The findings from the current analysis may not be applicable to scenarios of earthquake or other natural disasters in other regions.

\section{Conclusion}

PTSD remains a common mental health problem among survivors at five years after the 5.12 Wenchuan Earthquake in China. The major risk factors for such persistent PTSD included female gender, farmer occupation, old age and family member loss. Implementing psychological counseling for women, farmers, old age survivors and those with family member loss would be critical in mitigating the long-term risk of persistent PTSD.

\section{Competing interests}

The authors declare that they have no competing interests.

\section{Authors' contributions}

All authors contributed to conceive the study and refine its theoretic framework. LPZ, QZ and PXW supervised the field survey data collection and quality control. ZCL, YXL conducted the literature review. LPZ, QZ, PXW, YW and ZCL conducted data analyses and drafted the manuscript. All authors contributed to results interpretation, and in revising the article critically for important intellectual content, and approved the version to be published. LPZ was responsible for overall study implementation. All authors read and approved the final manuscript.

\section{Authors' information}

Li-Ping Zhang and Qian Zhao are co-first authors.

\section{Acknowledgements}

This study was supported by a research grant from the innovation experiment of students, Panzhihua University, and the Department of Science and Technology, Henan Province (grant number 102102310151). We would like to acknowledge all research staff (Xiao-Feng He, Cui-Ping He, Chao Tang, et al.) who contributed to data collection, and the government of Leigu community in Beichuan county for the support in facilitating the study.

\section{Author details}

${ }^{1}$ Medical school, Panzhihua University, Panzhihua, China. ${ }^{2}$ Institute of Public Health, School of Nursing, Henan University, Jinming Campus, Kaifeng, HN 475004, China. ${ }^{3}$ School of Public Health, Guangzhou Medical University, Guangzhou, China. ${ }^{4}$ Ministry of Education-Shanghai Key Laboratory of Children's Environmental Health, Xin Hua Hospital, Shanghai Jiao-Tong University School of Medicine, Shanghai, China.

Received: 16 September 2014 Accepted: 22 April 2015

Published online: 04 June 2015

\section{References}

1. China State Department official figures as of September 25, 2008. 2008. http://baike.baidu.com/link?url=uRsxtlgwn9l63igvmA7jnU5CaWd5w3AKE gcZT38gmFtRA2AskSMvnpFXkLnelq6ZFuEROJwx03e730iSdYKULa\&qq-pfto=pcqq.c2c. Accessed 15 Sept 2008.

2. Zhang YC, Ho SMY. Risk factors of posttraumatic stress disorder among survivors after the 512 Wenchuan Earthquake in China. PLoS ONE. 2011;6:1-6.

3. Wang L, Zhang YQ, Wang WZ, Shi ZB, Shen JH, Li M, et al. Symptoms of posttraumatic stress disorder among adult survivors three months after the Sichuan earthquake in China. J Trauma Stress. 2009:22:444-50.

4. Kun P, Han SC, Chen XC, Yao L. Prevalence and risk factors for posttraumatic stress disorder: a cross-sectional study among survivors of the Wenchuan 2008 earthquake in China. Depress Anxiety. 2009;26:1134-40.

5. Bryant RA, Guthrie RM. Maladaptive self-appraisals before trauma exposure predict posttraumatic stress disorder. J Consult Clin Psychol. 2007;75:812-5

6. Kessler RC, Berglund P, Demler $\mathrm{O}$, Jin R, Merikangas KR, Walters EE. Lifetime prevalence and age-of-onset distributions of DSM-IV disorders in the national comorbidity survey replication. Arch Gen Psychiatry. 2005;62:593-602.

7. Fullerton CS, Ursano RJ, Wang LM. Acute stress disorder, Posttraumatic stress disorder, and depression in disaster or rescue workers. Am J Psychiatry. 2004;161:1370-6.

8. Norris FH, Perilla JL, Riad JK, Kaniasty K, Lavizzo EA. Stability and change in stress resources and psychological distress following natural disaster: findings from Hurricane Andrew. Anxiety Stress Coping. 1999;12:363-96.

9. Zhang B, Zhang FG, Wang LP, Yu ZJ, Wang CQ, Wang SC, et al. A crosssectional study on the current prevalence of posttraumatic stress disorder in adults orphaned by Tangshan Earthquake in 1976. Chin Ment Health J. 2008:22:469-73.

10. Kuo HW, Wu SJ, Ma TC, Chiu MC, Chou SY. Posttraumatic symptoms were worst among quake victims with injuries following the Chi-chi quake in Taiwan. J Psychosom Res. 2007;62:495-500.

11. Kadri N, Berrada S, Douab S, Tazi I, Moussaoui D. Posttraumatic stress disorder in survivors of the Agadir earthquake (Morocco) in 1960. Encéphale. 2006:32:215-21.

12. Zhang LP, Wang PX, He HL. Assessment on the quality of life among survivors living in temporary settlements two years after the "5.12" Earthquake. Journal of hygiene research. 2011;40:744-7. 
13. Blay SL, Fillenbaum GG, Andreoli SB, Gastal FL. Prevalence and Concomitants of Arthritis in the Elderly in Rio Grande do Sul Brazil. PLoS One. 2012;7:e45418.

14. Weathers FW, Litz BT, Herman DS, Huska JA, Keane TM. The PTSD Checklist (PCL): Reliability, validity, and diagnostic utility. Paper presented at the 9th annual meeting of the International Society for Traumatic Stress Studies. 1993; San Antonio, Texas.

15. Heffner CL. Diagnostic and statistical manual of mental disorders fourth edition (DSM-IV). Washington DC: American Psychiatric Association; 1994

16. Yang $X Y$, Yang HA, Liu QG, Yang $L Z$. The research on the reliability and validity of PCL-C and influence factors. China J Health Psychol. 2007;15:6-9.

17. Ge $Y$, Wu JH, Sun $X H$, Zhang K. Enhanced mismatch negativity in adolescents with posttraumatic stress disorder (PTSD). Int J Psychophysiol. 2011;79:231-5.

18. Forbes D, Creamer M, Biddle D. The validity of the PTSD checklist as a measure of symptomatic change in combat-related PTSD. Behav Res Ther. 2001;39:977-86

19. Walker EA, Newman E, Dobie DJ, Ciechanowski P, Katon W. Validation of the PTSD checklist in an HMO sample of women. Gen Hosp Psychiatry. 2002;24:375-80.

20. Liu MX, Wang L, Shi ZB, Zhang Z, Zhang K, Shen JH. Mental health problems among children one-year after Sichuan Earthquake in China: a follow-up study. PLOS ONE. 2011;6:1-6.

21. Zhang LP, Wang PX, Li YF, Hu QX. Assessment of the posttraumatic symptoms among survivors three years following Wenchuan Earthquake. Chinese Journal of Preventive Medicine. 2012;46:708-12.

22. Phillips MR, Zhang JX, Shi QC, Song ZQ, Ding ZJ, Pang ST, et al. Prevalence, treatment, and associated disability of mental disorders in four provinces in china during 2001-05: an epidemiological survey. Lancet. 2009;373:2041-53.

23. Ke X, Liu CJ, Li N. Social support and Quality of Life: a cross-sectional study on survivors eight months after the 2008 Wenchuan earthquake. BMC Public Health. 2010;10:573-84.

24. Yilmaz V, Cangur S, Celik HE. Sex difference and earthquake experience effects on earthquake victims. Personal Individ Differ. 2005;31:305-8

25. Jia ZB, Tian WH, Liu WZ, Cao Y, Yan J, Shun ZS. Are the elderly more vulnerable to psychological impact of natural disaster? A population-based survey of adult survivors of the 2008 Sichuan earthquake. BMC Public Health. 2010;10:1-11.

26. Pirkola S, Sund R, Sailas E, Wahlbeck K. Community mental-health services and suicide rate in Finland: a nationwide small-area analysis. Lancet. 2009;373:147-53.

27. Terhakopian A, Sinaii N, Engel CC, Schnurr PP, Hoge CW. Estimating population prevalence of posttraumatic stress disorder: an example using the PTSD checklist. J Trauma Stress. 2008;21:290-300.

\section{Submit your next manuscript to BioMed Central and take full advantage of:}

- Convenient online submission

- Thorough peer review

- No space constraints or color figure charges

- Immediate publication on acceptance

- Inclusion in PubMed, CAS, Scopus and Google Scholar

- Research which is freely available for redistribution 